\title{
Electrical Properties of the Al/CuInSe 2 Thin Film Schottky Junction
}

\author{
S. Hamrouni ${ }^{1,2}{ }^{*}$, M. F. Boujmil2, K. Ben Saad ${ }^{1,2}$ \\ ${ }^{1}$ College of Science and Art at Rass, Qassim University, Qassim, Saudi Arabia \\ 'Laboratoire de Photovoltaïque, Centre de Recherches et des Technologies de l'Energie, Technopole de \\ Borj-Cédria, Hammam-Lif, Tunisia \\ Email: sahbihamrouni82@yahoo.fr
}

Received 8 September 2014; revised 23 October 2014; accepted 9 November 2014

Copyright (C) 2014 by authors and Scientific Research Publishing Inc.

This work is licensed under the Creative Commons Attribution International License (CC BY).

http://creativecommons.org/licenses/by/4.0/

(c) (i) Open Access

\begin{abstract}

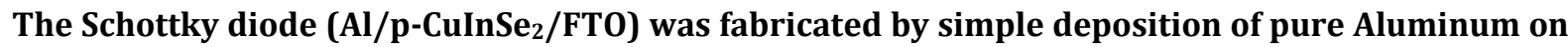
the front side of the CuInSe $e_{2}$ thin film. We have investigated its electrical characteristics by measuring the current-voltage (I-V), the capacitance-voltage (C-V) and the electrical impedance in the range of temperature $(300 \mathrm{~K}-425 \mathrm{~K})$. At room temperature, this heterostructure has shown nonideal Schottky behavior with 3.98 as ideality factor and $38 \mu \mathrm{A} / \mathrm{cm}^{2}$ as a reverse saturated current density. The $\mathrm{C}-\mathrm{V}$ measured at $100 \mathrm{kHz}$ has shown non-linear behavior and an increase with temperature. Similarly, we have estimated, at room temperature, the carrier doping density, the built-in potential and the depletion layer width which are of about $8.66 \times 10^{15} \mathrm{~cm}^{-3}, 1.12 \mathrm{~V}$ and $0.37 \mu \mathrm{m}$ respectively. By the impedance spectroscopy technique, we have found a decrease with temperature of all the serial resistance $R_{s}$, the parallel resistance $R_{p}$ and the capacitance $C_{p}$. The frequency dependence of the imaginary part of this impedance was carried out to characterize the carrier transport properties in the heterostructure. From the Arrhenius diagram, we have estimated the activation energy at $460 \mathrm{meV}$. An equivalent electrical circuit was used for modeling these results.
\end{abstract}

\section{Keywords}

Schottky Junction, CuInSe 2 Thin Films, IV and CV Characteristics, Impedance Spectroscopy, Temperature Effects

\section{Introduction}

Photovoltaic (PV) effect was discovered in 1839, but it remained a laboratory curiosity until the mid 1950s when USA space program attempted to power satellites with PV cells. In 1954, single crystal silicon (sc-Si) PV cells of

${ }^{*}$ Corresponding author. 
$6 \%$ efficiency were reported at Bell Laboratories [1]. During the energy crisis of the early 1970s, both public and private sectors became interested in applications of PV energy generation. Initial efforts focused on lowering the cost of sc-Si solar cell modules since the basic technology already was well developed [2] [3], While polycrystalline silicon (pc-Si) solar cell module technology was introduced to further lower manufacturing costs. However, its cost advantages were confronted by its lower efficiency which was approximately equal to $9.2 \%$ [4]. To respond to the potential demand in the power generation market, research and development efforts were shifted gradually to other polycrystalline thin film material systems like ternary chalcopyrite semiconductors $\left(\mathrm{CuInSe}_{2}\right.$, $\mathrm{CuGaSe}_{2}, \mathrm{AgInSe}_{2}$, etc.) which gave efficiency from 6\% to $16 \%$ [5]-[9]. These materials systems are being considered seriously as the basis of PV module future technologies for terrestrial power generation. On the other hand, several techniques have been actually used for the preparation of chalcopyrite films. We can mention some of them as electrodeposition [10] [11], flash evaporation [12], r.f. sputtering [13], thermal evaporation [14], solution growth [15], hot press [16], hot wall method [17] [18] and pulse laser ablation [19] and so on.

Although metal-semiconductor (MS) contacts are the most used as rectifying contacts for the fabrication of electronic devices, they are frequently used in solar cells, in light detectors and in integrated circuits [20]-[26]. The performance and the reliability of a Schottky diode are considerably influenced by the quality of the interface between the deposited metal and the contact surface of the semiconductor [27]. The most important physical parameters characterizing this junction are its potential barrier and its ideality factor. The existence of native oxide layer in its interface has a direct effect on the carrier charges transport and modifying the electrical properties [28]. The Schottky junction $\mathrm{Al} / \mathrm{CuInSe}_{2}$ is one of the simplest MS contact devices. The p-type junctions, like $\mathrm{p}-\mathrm{CuInSe} \mathrm{S}_{2}$, have been analyzed and have given useful information concerning the effects of the physical defects on the electrical carrier transport through the junctions [29] [30]. As proved experimentally, most of these junctions have an electrical behavior close to the theoretical ideal thermionic emission current model usually used [31]-[36], although the study of the temperature dependence on the current-voltage (IV) and the capacitancevoltage $(\mathrm{CV})$ characteristics of these junctions gives more detailed information about their conduction processes and the nature of the potential barrier [37]-[43].

In this work, we have fabricated the Schottky junction $\mathrm{Al} / \mathrm{p}-\mathrm{CuInSe}_{2}$ by electrodeposition technique to investigate the dominant current transport conduction mechanisms. The temperature dependence of the current-voltage, capacitance-voltage characteristics and the impedance measurements were analyzed in order to understand the effects of interface and the thermionic emission mechanism on this Schottky junction.

\section{Experimental Details}

The CIS ( $\left.\mathrm{CuInSe}_{2}\right)$ films have been electrodeposited on FTO substrates and treated at $400^{\circ} \mathrm{C}$ in vacuum during $20 \mathrm{~min}$ as described in our previous works [10]. In order to form the Al/p-CIS/FTO Schottky junction, aluminum electrodes were evaporated on this structure as shown in Figure 1, following by an annealing in air at different temperature varying in the range $50^{\circ} \mathrm{C}-125^{\circ} \mathrm{C}$.

Their electrical properties were tested by using the AC/DC Keithley Instrument Model 4200-SCS Semiconductor Characterization System by measuring their I-V, C-V and their electrical impedances which were performed with a sweep of voltage.

\section{Results and Discussion}

\subsection{Current-Voltage Characteristics}

Schottky barriers on semiconductor are of interest not only because of their applications as rectifying contacts but also due to the insight they afford into the nature of bounding and defect levels in solids. Generally, it is assumed that the forward bias current of the Schottky diodes is due to thermionic emission mechanism.

The theoretical current-voltage characteristic of the $p-n$ junction diode is given by the following known relationship [44]:

$$
I=I_{0}\left[\exp \left(\frac{q}{n K T}\left(V-R_{s} I\right)\right)-1\right]
$$

where $q$ is the carrier unit charge, $I_{0}$ is the reverse saturation current, $V$ the applied voltage, $R_{s}$ the serial 


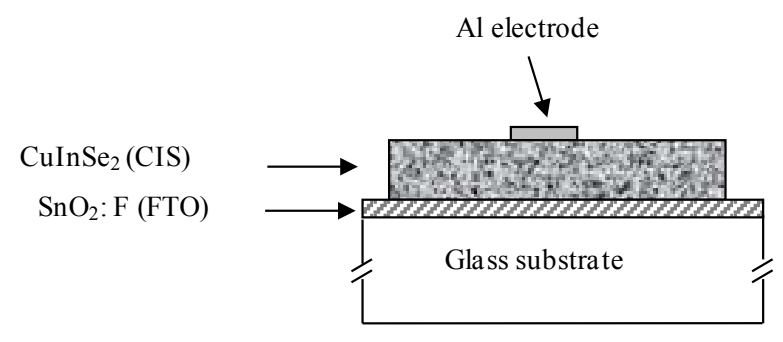

Figure 1. The structure of Al/p-CIS/FTO Schottky junction.

resistance, $T$ the absolute temperature and $n$ the ideality factor.

Experimentally, the current-voltage characteristic studied under forward and reverse bias conditions of the $\mathrm{Al} / \mathrm{p}$-CIS/FTO junction in dark and at room temperature is shown in Figure 2. The rectifying behavior confirms that this junction acts like a Shottky diode.

The approximated Equation (1) up to the threshold potential can be written in the following logarithmic form:

$$
\ln I=\ln I_{0}+\frac{q}{n K T}\left(V-R_{s} I\right)
$$

Figure 3 shows, at room temperature, the I-V characteristic which shows the reverse current saturation about $38 \mu \mathrm{A}$.

Moreover, the differentiation of the last equation may provide the following form:

$$
\frac{\mathrm{d} V}{\mathrm{~d}(\ln I)}=R_{s} I+\frac{n K T}{q}
$$

Figure 4 illustrates, at room temperature, this variation versus the current density $I$. It has, in fact, a linear behavior and we can easily extract both the serial resistance $R_{s}$ and the ideality factor $\mathrm{n}$ which are estimated to be $137.5 \Omega$ and 3.98 respectively. This last one has high value than the ideal factor $(n=1)$ which is possibly due to the potential drop and the recombination current traversing the interfacial layer [37].

\subsection{Capacitance-Voltage Measurements}

The depletion layer capacitance $C$ per unit area can be given by the known expression:

$$
\mathrm{C}^{-2}=\frac{2}{q \varepsilon_{s} N_{A}}\left[V_{0}-V\right]
$$

where, $\varepsilon_{s}$ is the dielectric constant of semiconductor, $V$ the applied voltage, $N_{A}$ the carrier acceptors concentration and $V_{0}$ is the built-in potential in semiconductor devices which is equal to the potential across the depletion region in thermal equilibrium.

In dark, the capacitance-voltage $\mathrm{C}^{-2}-\mathrm{V}$ in the reverse bias voltage, at different temperatures and at $100 \mathrm{kHz}$, was studied. It is clear from Figure 5 that at reverse bias ( $V \leq-3$ Volts) the capacitance is bias dependent which indicates that the junction is fully depleted. As the bias increases, a locally linear behavior is obtained for all temperatures.

According to Equation (3), we have extracted from Figure 6 the built-in potential $V_{0}$ and the carrier acceptors concentration $N_{A}$ at different temperatures for $\mathrm{Al} / \mathrm{p}-\mathrm{CuInSe} \mathrm{S}_{2}$ Schottky junction. We can see that the $V_{0}$ decrease when the temperature increases and lies between 1.12 and $0.21 \mathrm{~V}$ and these results are comparable with other works in literatures [28] [45] [46]. While, the carrier doping density $N_{A}$ value is slightly increased with temperature and varied from $8.66 \times 10^{15} \mathrm{~cm}^{-3}$ at $300 \mathrm{~K}$ to $1.57 \times 10^{16} \mathrm{~cm}^{-3}$ at $425 \mathrm{~K}$. We note that the effective carrier concentration in this thin Schottky film is in order of $10^{15} \mathrm{~cm}^{-3}$. These results are also in good agreement with those reported by Zhang et al. and other authors [47]-[49].

Thus, the annealing of the junction modifies the electrical properties in the layers. This can be attributed to the presence of the interfacial thin native oxide layer between the metal and semiconductor [50] or by the inter-diffusion between the metal layer and the CIS film and may be also due to the existence of a trap centers in the junction [51] [52]. 


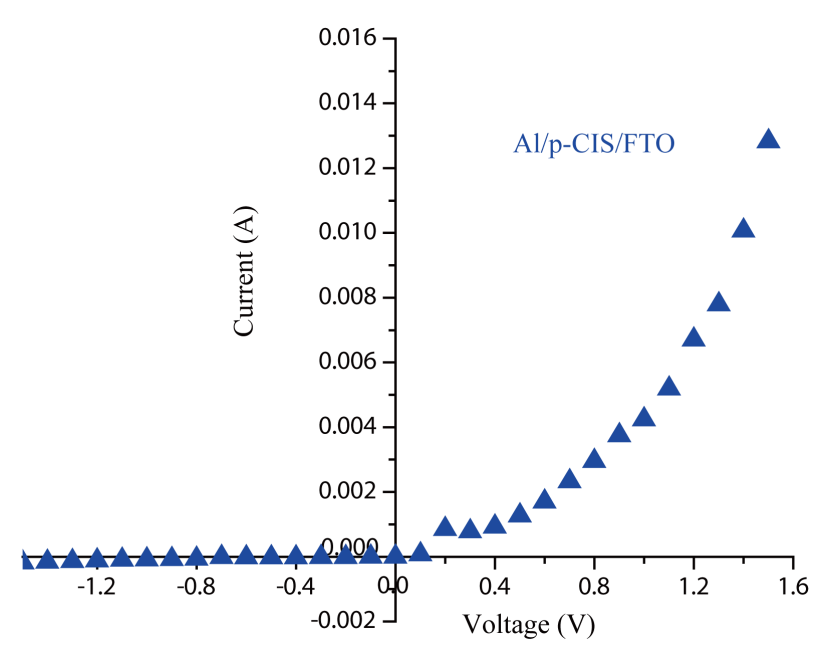

Figure 2. Experimental current-voltage characteristic of $\mathrm{Al} / \mathrm{p}-\mathrm{CIS}$ junction at room temperature.

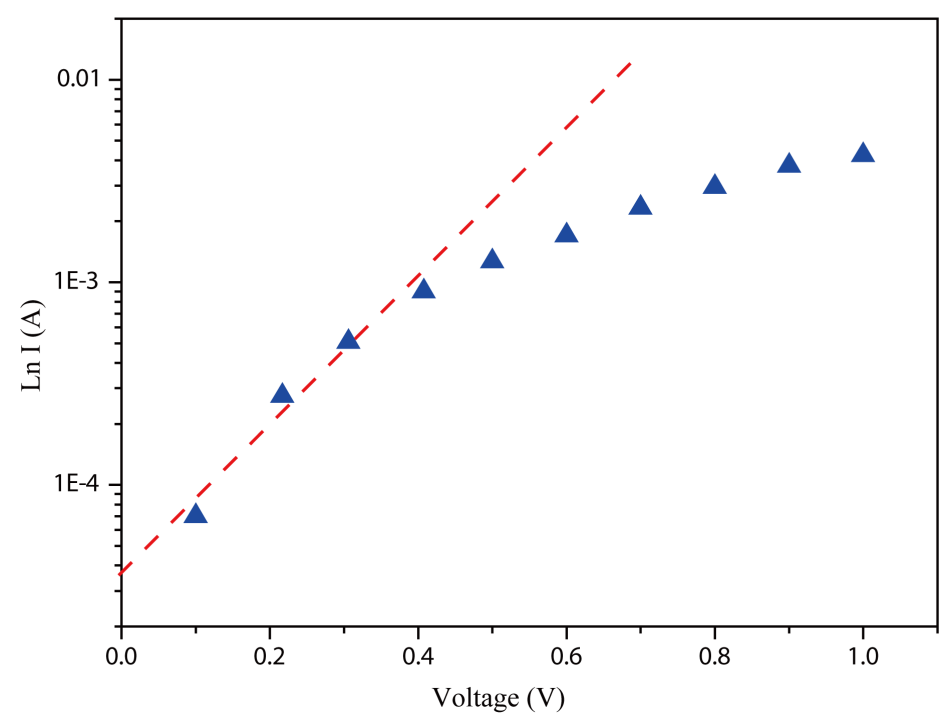

Figure 3. The logarithm of the current density $\ln (I)$ vs. the forward bias voltage $(V)$ of The $\mathrm{Al} / \mathrm{p}$-CIS Schottky junction at room temperature.

In addition, the defects in semiconductor material play an important role as traps or as recombination centers depending on the capture cross section of the electrons and holes. Due to these defects and to the presence of deep impurities in the depletion region, the rectifying contact capacitance may be varying. The rectifying devices' traps reduce the free carrier density whereas recombination centers produce generation-recombination current. When the temperature increases, there is a decrease of the built-in potential $V_{0}$ and an increase of the carrier concentration $N_{A}$ (Figure 6). This effect may be attributed to the effect of traps [53].

It is known that the depletion layer width, formed in the junction, of the $n^{+}$-side of the metal is much smaller than the $p$-side of the semiconductor and can be neglected, and then the layer width $W$ is only reduced to the $\mathrm{p}$-side region and is given by the following expression:

$$
W=\left(\frac{2 \varepsilon_{s} V_{0}}{q N_{A}}\right)^{1 / 2}
$$

The potential difference $V_{n}$ between the Fermi level and the top of the valence band in the CIS can be obtained by the following relationship: 


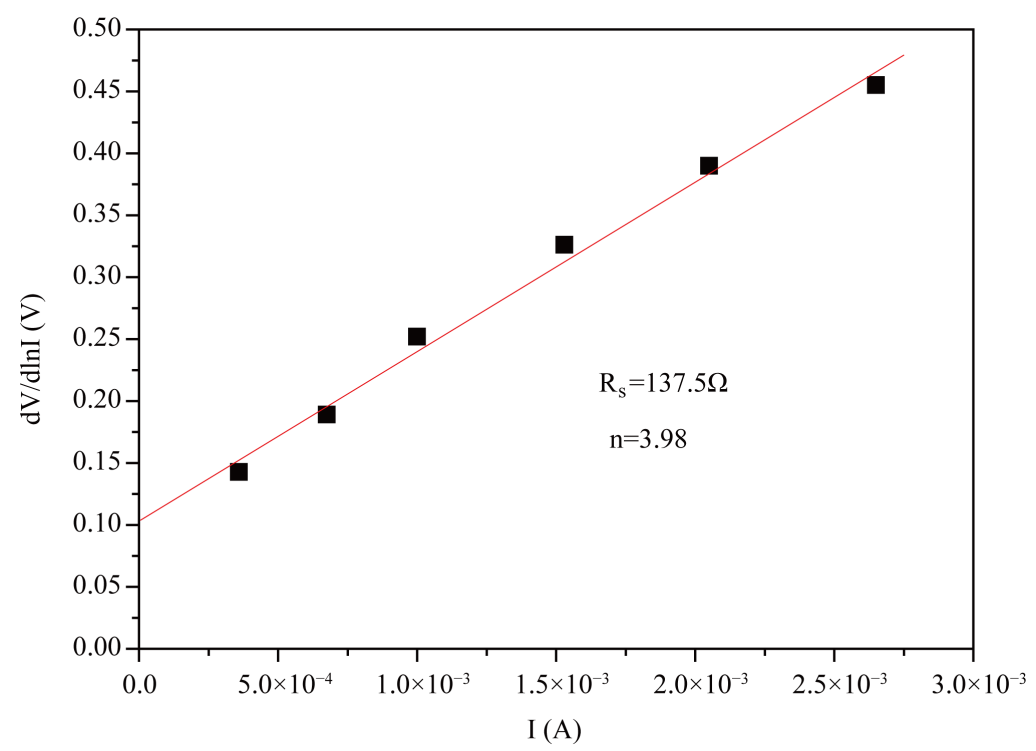

Figure 4. $\frac{\mathrm{d} V}{\mathrm{~d}(\ln I)}$ versus the current density at room temperature for $\mathrm{Al} / \mathrm{p}$-CIS Schottky junction.

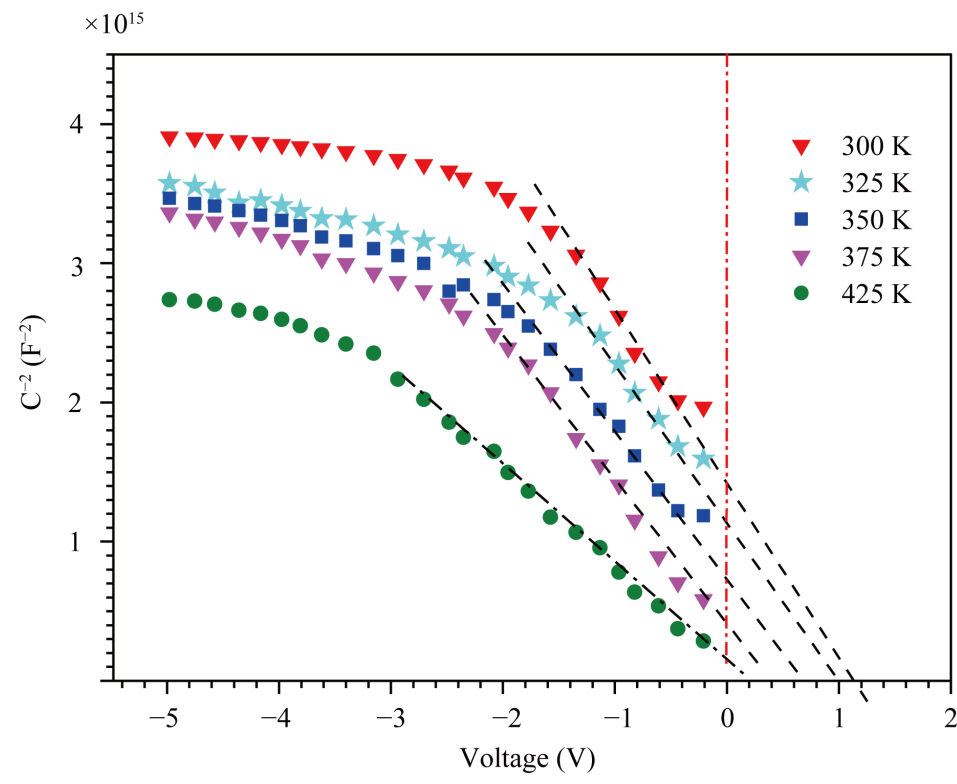

Figure 5. $\mathrm{C}^{-2}-V$ of the $\mathrm{Al} / \mathrm{p}$-CIS Schottky junction at different temperatures.

$$
V_{n}=\frac{K T}{q} \ln \frac{N_{v}}{N_{A}}
$$

where $N_{v}$ is effective density of states in the valence band of the CIS $\left(1.5 \times 10^{19} \mathrm{~cm}^{-3}[54]\right)$.

Thus, the barrier height value for the $\mathrm{Al} / \mathrm{p}-\mathrm{CuInSe}{ }_{2}$ device is calculated by:

$$
\varphi_{b}=V_{0}+V_{n}
$$

Figure 7 shows the variation of the layer width and the barrier height with temperature. We observe that the depletion layer width W decreases with increasing temperature due to the increasing of the carrier density $N_{A}$. 


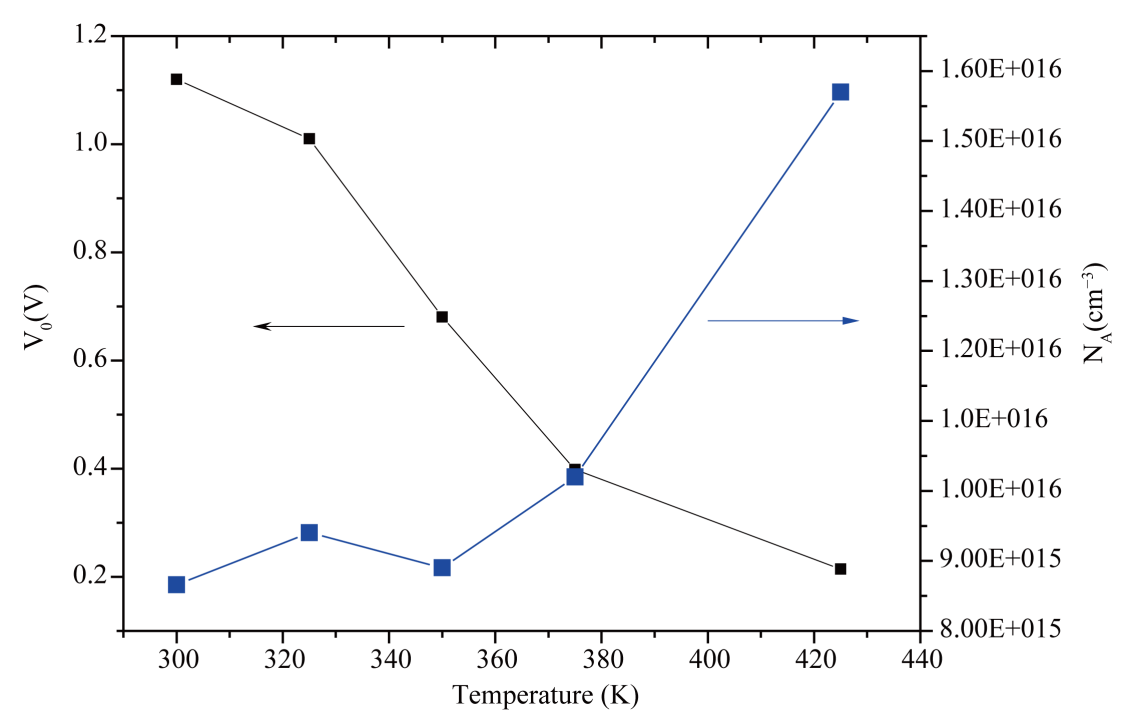

Figure 6. Temperature dependence of $V_{0}$ and $N_{A}$ for the Al/p-CIS Schottky junction.

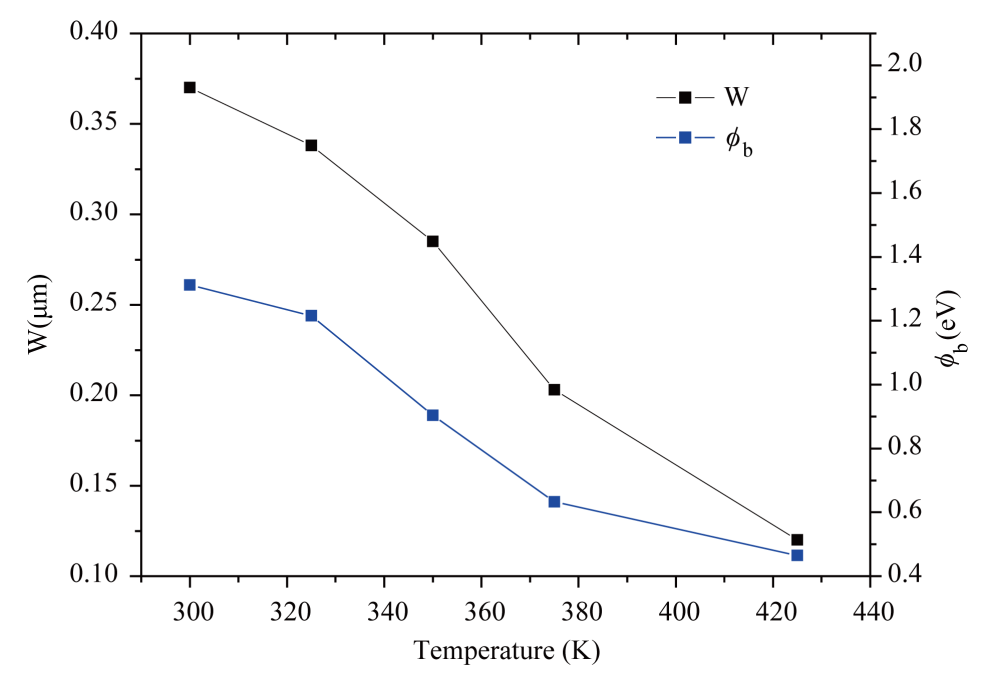

Figure 7. The depletion layer width $W$ and the barrier height $\varphi_{b}$ of the Al/p-

CIS junction as a function of the temperature.

\subsection{Impedance Spectroscopy}

The impedance spectra of the Al/p-CIS/FTO heterostructure at zero bias for various temperatures are shown in Figure 8. The electrical response can be fitted as an equivalent $\mathrm{AC}$ circuit composed by a single parallel resistor $R_{p}$ and capacitor $C_{p}$ network connected to a serial resistor $R_{s}$ as shown in Figure 9. Its real and imaginary impedance parts $Z^{\prime}$ and $Z^{\prime \prime}$ may be written as:

$$
Z^{\prime}=R_{s}+\frac{R_{p}}{1+\omega^{2} C^{2} R_{p}^{2}}, \quad Z^{\prime \prime}=\frac{\omega C R_{p}^{2}}{1+\omega^{2} C^{2} R_{p}^{2}}
$$

The values of the serial resistance $R_{s}$ and the total resistance $\left(R_{s}+R_{p}\right)$ are obtained from the low and high frequency intercepts on the $Z^{\prime}$ axis respectively. The value of the capacitance was found to be slightly frequency dependent. Figure 10 and Figure 11 illustrate the evolution of the equivalent circuit parameters as a function with temperature. It can be observed that all the serial and the parallel resistances and the capacitance decrease with increasing temperature due probably the improvement of the junction structure.

We mention different results for the serial resistance values obtained by the two different methods, from (DC) 


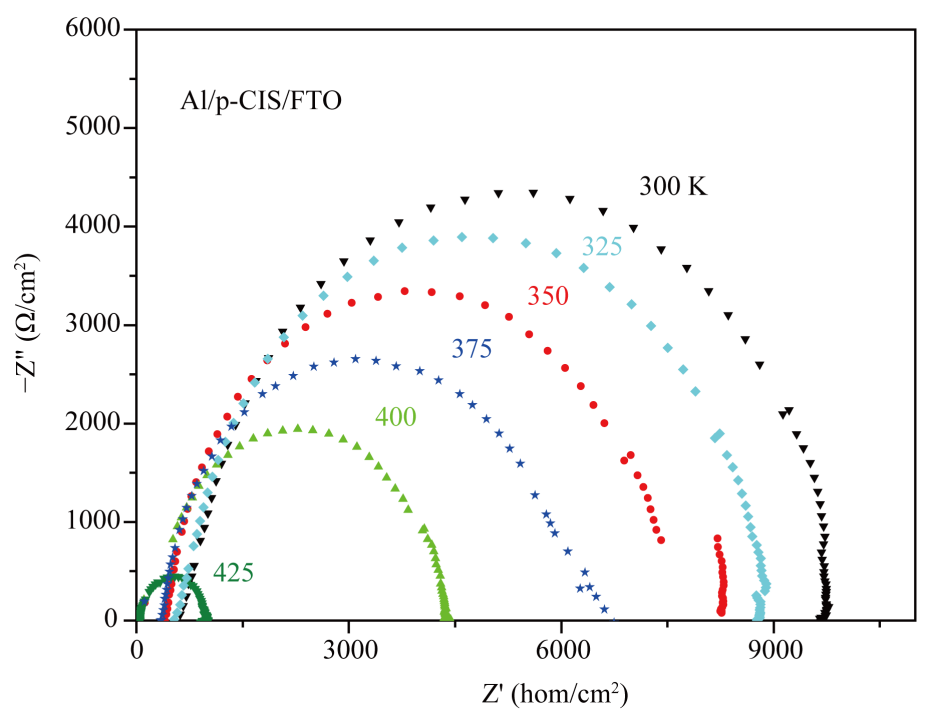

Figure 8. Nyquist diagram of a $\mathrm{Al} / \mathrm{p}$-CIS heterojunction at different temperatures.

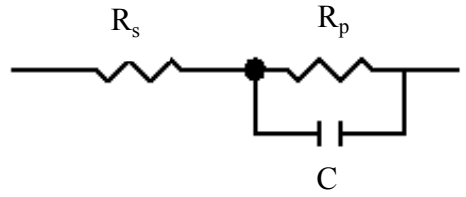

Figure 9. Equivalent circuit for $\mathrm{Al} / \mathrm{p}$-CIS Schottky Diode. $R_{s}$ represents the series resistance, $R_{p}$ the parallel resistance and $C$ the capacitance.

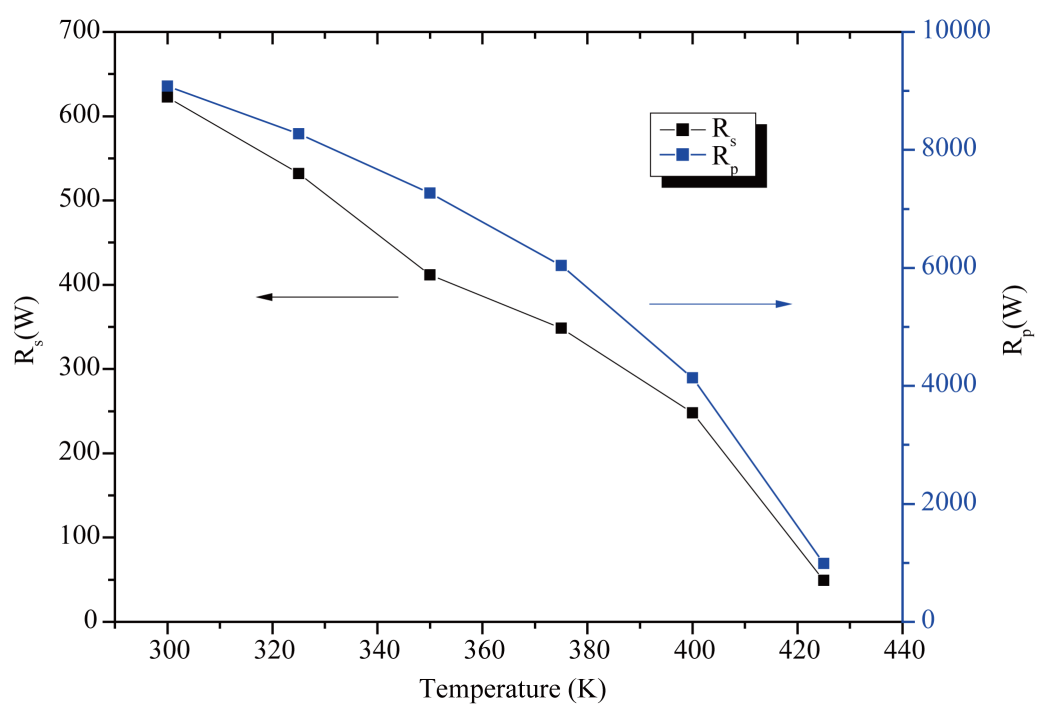

Figure 10. The variation of the series resistance and parallel resistance for different temperatures of $\mathrm{Al} / \mathrm{p}$-CIS Schottky diode.

$\mathrm{I}-\mathrm{V}$ and from (AC) impedancemetry, which are respectively $173.5 \Omega$ and $622.5 \Omega$ at room temperature. The first value is different from the second one and this difference is due to the insufficiency of the conduction model where we don't have take account to the different diffusion processes of the carriers.

In fact, by introducing the previous values of $R_{s}, R_{p}$ and $\mathrm{C}$ in the theoretical real and imaginary part of the 


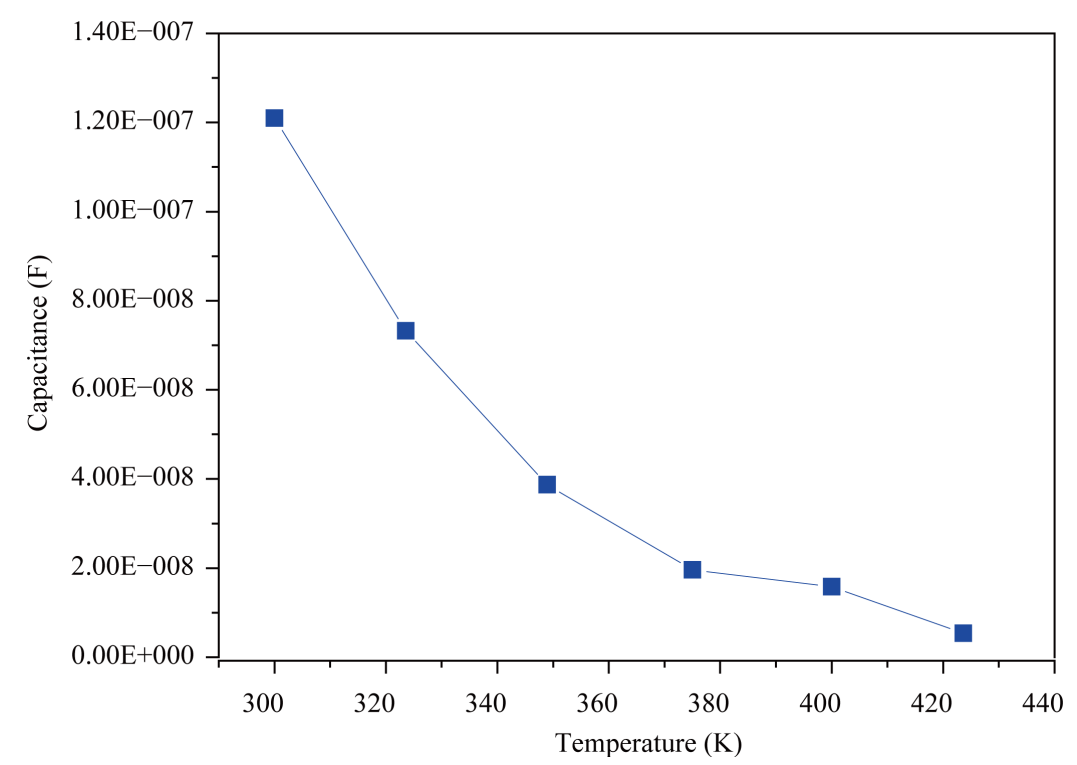

Figure 11. The variation of the space-charge capacitance vs. temperature for $\mathrm{Al} / \mathrm{p}$ CIS Schottky Diode.

complex impedance, we have found a good fitting in the range of frequencies $1 \mathrm{kHz}$ to $10 \mathrm{MHz}$ as shown in Figure 12 for $300 \mathrm{~K}$. This result is also verified for the other chosen temperatures.

When increasing the temperature, the cut-off frequency of the imaginary part of the impedance, shown in Figure 13, shifts towards the higher frequencies, and satisfies the theoretical model of the hole traps interacting with the valence band [55]:

$$
\omega=A v_{t h} \sigma_{p} N_{V} \exp -\frac{E_{a}}{K T}
$$

where $A$ is the dimensionless quantity related to the degeneracy factor of the trap and the fixed charge within the depletion region, $v_{t h}$ the average thermal velocity of the holes in the valence band, $\sigma_{p}$ the capture crosssection of the trap and $E_{a}$ is the energy difference between the trap level and the valence band. Figure 14 shows the Arrhenius diagram of the $\ln (\omega)$ versus the inverse of temperature which is linear and proportional to the Activation energy $E_{a}$ estimated to $0.46 \mathrm{eV}$.

\section{Conclusions}

The Al/CIS/FTO heterojunction was fabricated and studied by using I-V, C-V and impedance measurements in the range of temperature $300 \mathrm{~K}-425 \mathrm{~K}$. The rectifying behavior confirms that this junction behaves as a Schottky diode with p-type absorber layer. The high value found for the ideality factor is probably due to both the potential drop and the recombination through the interfacial layer. C-V measurements reveal that the carrier concentration of annealed CIS films is in the order of $10^{15} \mathrm{~cm}^{-3}$. In addition, we have observed that the depletion layer width and the barrier height decrease with temperature. We have also given, from the impedance spectra, the electrical equivalent circuit and we have found that their parameters $\left(R_{s}, R_{p}\right.$ and $\left.C\right)$ decrease when annealing temperature increases. Two different results, for the serial resistance $R_{s}$, have been deduced from the DC and AC measurements. This difference is due to the insufficiency of the conduction model where we don't have taken into account the different diffusion processes and the existence of trap levels.

The study on temperature of our junction shows some information in transport phenomenon. It shows the quality of the interface between thin layers. Those results are favorable for preparing thin film solar cells with p-CIS as absorber layer. In addition, the electrodeposited absorber layer of $\mathrm{CuInSe}_{2}$ has shown good stability with weak resistance in the interface. Such heterojunction fabrication processes will significantly help the realization of low-cost thin films and this technique may be concurrent to other ones because it is economic, technologically simple and allows the possibility of deposition over large surface areas for the PV solar cells fabrication. 


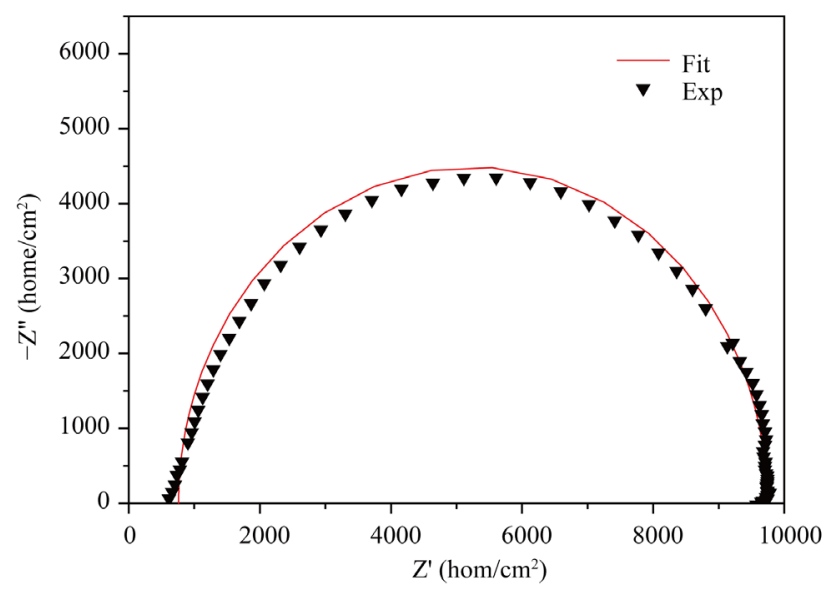

Figure 12. Comparison of the experimental and the theoretical Nyquist diagram at ambient temperature.

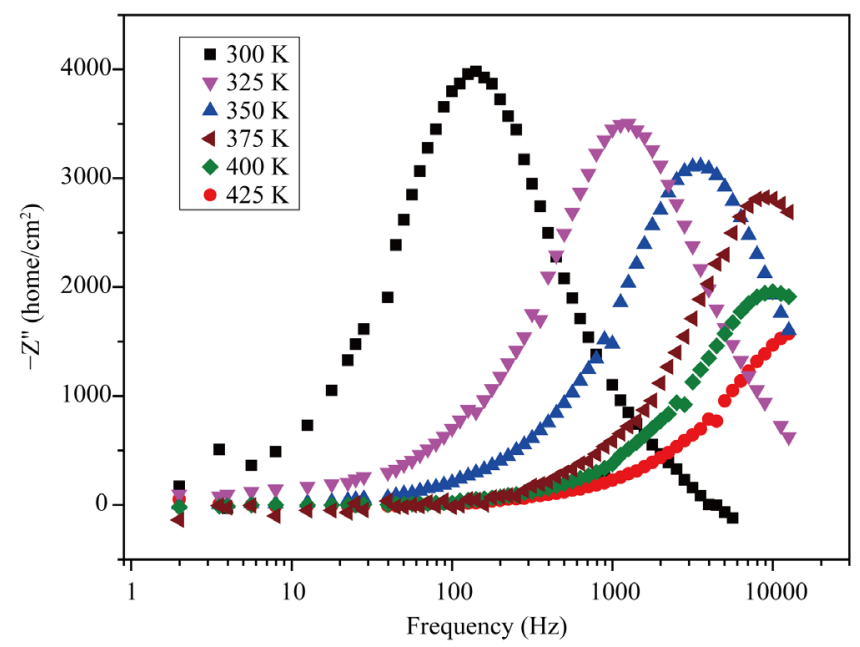

Figure 13. Variation of the cut-off frequency of the imaginary part $-Z^{\prime \prime}$ at various temperatures.

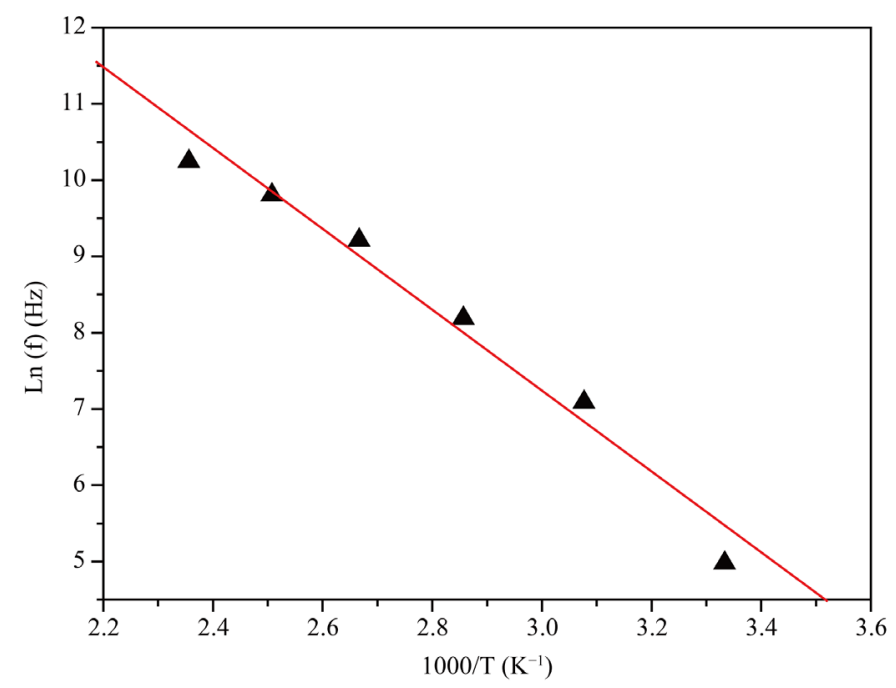

Figure 14. Arrhenius diagram of the cut-off frequency. 


\section{Acknowledgements}

This work was financed by the "Ministere de l' Enseignement Superieur de Tunis" and by "Qassim University, Kingdom of Saudi Arabia" on the project No. 1504.

\section{References}

[1] Singh, J. and Shimakawa, K. (2003) Advances in Amorphous Semiconductors. Advances in Condensed Matter, 5, 336 p.

[2] Meier, J., Dubail, S. and Cuperus, J. (1998) Recent Progress in Micromorph Solar Cells. Journal of Non-Crystalline Solids, 227-230, 1250-1256. http://dx.doi.org/10.1016/S0022-3093(98)00352-4

[3] Yamamoto, K., Yoshimi, M. and Tawada, Y. (2000) Thin Film Si Solar Cell Fabricated at Low Temperature. Journal of Non-Crystalline Solids, 266-269, 1082-1087. http://dx.doi.org/10.1016/S0022-3093(99)00907-2

[4] Matsuyama, T., Terada, N. and Baba, T. (1996) High-Quality Polycrystalline Silicon Thin Film Prepared by a Solid Phase Crystallization Method. Journal of Non-Crystalline Solids, 198-200, 940-944. http://dx.doi.org/10.1016/0022-3093(96)00091-9

[5] Pathak, D., Wagner, T., Šubrt, J. and Kupcik, J. (2014) Characterization of Mechanically Synthesized AgInSe 2 Nanostructures. Canadian Journal of Physics, 92, 789-796. http://dx.doi.org/10.1139/cjp-2013-0546

[6] Pathak, D., Bedi, R.K. and Kaur, D. (2010) Growth of Heteroepitaxial AgInSe ${ }_{2}$ Layers on Si (100) Substrates by Hot Wall Method. Optoelectronics and Advanced Materials, 4, 657-661.

[7] Pathak, D., Bedi, R.K. and Kaur, D. (2010) Characterization of AgInSe F $_{2}$ Films Deposited by Hot Wall Vacuum Evaporation Method. Materials and Manufacturing Processes, 25, 1012-1017. http://dx.doi.org/10.1080/10426910903367360

[8] Bhattacharya, R.N., Hiltner, J.F. and Batchelor, W. (2000) 15.4\% CuIn $\operatorname{In}_{(1-x)} \mathrm{Ga}_{\mathrm{x}} \mathrm{Se}_{2}$-Based Photovoltaic Cells from Solution-Based Precursor Films. Thin Solid Films, 361-362, 396-399. http://dx.doi.org/10.1016/S0040-6090(99)00809-3

[9] Ramesh, P.P., Uthana, S., Srinivasalu, S.B. and Jayarama, P.R. (1996) Photoconductive Response of Polycrystalline n-AglnSe ${ }_{2}$ Thin Films. Vacuum, 47, 211-213. http://dx.doi.org/10.1016/0042-207X(95)00233-2

[10] Hamrouni, S., AlKhalifah, M.S., Boujmil, M.F. and Ben Saad, K. (2014) Preparation and Characterization of CuInSe 2 Electrodeposited Thin Films Annealed in Vacuum. Applied Surface Science, 292, 231-236. http://dx.doi.org/10.1016/j.apsusc.2013.11.123

[11] Lee, H., Lee, W., Kim, J.Y., Ko, M.J., Kim, K., Seo, K., et al. (2013) Highly Dense and Crystalline CuInSe 2 Thin Films Prepared by Single Bath Electrochemical Deposition. Electrochimica Acta, 87, 450-456. http://dx.doi.org/10.1016/j.electacta.2012.09.118

[12] Chen, P., Bolmont, D. and Sebenne, C.A. (1984) The Ordered Overlayer Growth of Germanium on Si(111) $(7 \times 7)$. Thin Solid Films, 111, 367-373. http://dx.doi.org/10.1016/0040-6090(84)90328-6

[13] Weir, R.D., Jessop, P.E. and Garside, B.K. (1987) Growth and Annealing of AgInSe ${ }_{2}$ Thin Films. Canadian Journal of Physics, 65, 1033-1036. http://dx.doi.org/10.1139/p87-169

[14] El-Korashy, A., Abdel-Rahim, M.A. and El-Zahed, H. (1999) Optical Absorption Studies on AgInSe and AgInTe $_{2}$ Thin Films. Thin Solid Films, 338, 207-212. http://dx.doi.org/10.1016/S0040-6090(98)00982-1

[15] Sharma, R.P. (1995) Influence of Annealing in Vacuum on Opto-Electronic Characteristics of Solution Grown AgInSe 2 Films. Indian Journal of Pure and Applied Physics, 33, 711.

[16] Yoshino, K., Kinoshita, A., Shirahata, Y., Oshima, M., Nomoto, K., Yoshitake, T., Ozaki, S. and Ikari, T. (2008) Structural and Electrical Characterization of $\mathrm{AgInSe}_{2}$ Crystals Grown by Hot-Press Method. Journal of Physics, 100, Article ID: 042042. http://dx.doi.org/10.1088/1742-6596/100/4/042042

[17] Pathak, D., Bedi, R.K., Kaur, D. and Kumar, R. (2011) $200 \mathrm{MeV}$ Ag Ion Beam Induced Modifications in AgInSe 2 Films Deposited by Hot Wall Vacuum Evaporation Method. Chalcogenide Letters, 8, 213-222.

[18] Mustfa, H., Hunter, D., Pradhan, A.K., Roy, U.N., Cui, Y. and Burger, A. (2007) Synthesis and Characterization of $\mathrm{AgInSe}_{2}$ for Application in Thin Film Solar Cells. Thin Solid Film, 515, 7001-7004.

[19] Pathak, D., Bedi, R.K. and Kaur, D. (2009) Growth of AgInSe $\operatorname{In}_{2}$ on Si(100) Substrate by Pulse Laser Ablation. Surface Review and Letters, 16, 917. http://dx.doi.org/10.1142/S0218625X09013487

[20] Chopra, N.G., Luyken, R.J., Cherry, K., Crespi, V.H., Cohen, M.L., Louie, S.G. and Zettl, A. (1995) Boron Nitride Nanotubes. Science, 269, 966-967. http://dx.doi.org/10.1126/science.269.5226.966

[21] Rhoderick, E.H. and Williams, R.H. (1988) Metal-Semiconductor Contacts. Vol. 48, Oxford University Press, Oxford, 20 . 
[22] Dimitruk, N.L., Borkovskaya, O.Y., Dmitruk, I.N., Mamykin, S.V., Horvath, Zs.J. and Mamontova, I.B. (2002) Morphology and Interfacial Properties of Microrelief Metal-Semiconductor Interface. Applied Surface Science, 190, 455460. http://dx.doi.org/10.1016/S0169-4332(01)00918-7

[23] Saha, A.R., Chattopadhyay, S., Das, R., Bose, C. and Maiti, C.K. (2006) Determination of the Interface Properties of Ni-Silicided Strained Si/SiGe Heterostructure Schottky Diodes Using Capacitance-Voltage Technique. Solid-State Electronics, 50, 1269-1275. http://dx.doi.org/10.1016/j.sse.2006.06.001

[24] Osvald, J. and Horvath, Zs.J. (2004) Theoretical Study of the Temperature Dependence of Electrical Characteristics of Schottky Diodes with an Inverse Near-Surface Layer. Applied Surface Science, 234, 349-354. http://dx.doi.org/10.1016/j.apsusc.2004.05.046

[25] Chand, S. and Kumar, J. (1997) Effects of Barrier Height Distribution on the Behavior of a Schottky Diode. Journal of Applied Physics, 82, 5005-5009. http://dx.doi.org/10.1063/1.366370

[26] Rhoderick, E.H. and Williams, R.H. (1988) Metal-Semiconductor Contacts. Vol. 19, Oxford University Press, Oxford, 252.

[27] Aydin, M.E., Yeldirm, N. and Türüt, A. (2007) Temperature-Dependent Behavior of Ni/4H-nSiC Schottky Contacts. Journal of Applied Physics, 102, Article ID: 043701. http://dx.doi.org/10.1063/1.2769284

[28] Chan, C.L. and Shih, I. (1990) Al/p-CuInSe 2 Metal-Semiconductor Contacts. Journal of Applied Physics, $68,156$. http://dx.doi.org/10.1063/1.347108

[29] Koscielniak-Mucha, B. and Opanowicz, B.A. (1994) Electronic Properties of Semiconductor Interfaces. Physica Status Solidi (a), 141, 67.

[30] Magomedov, M.A., Prochukhan, V.D. and Rud, Yu.V. (1992) Electronic Properties of Semiconductor Interfaces. Soviet Physics Semiconductors, 26, 1123.

[31] Chawanda, A., Mtangi, W., Auret, F.D., Nel, J., Nyamhere, C. and Diale, M. (2012) Current-Voltage Temperature Characteristics of Au/n-Ge (100) Schottky Diodes. Physica B: Condensed Matter, 407, 1574-1577. http://dx.doi.org/10.1016/j.physb.2011.09.089

[32] McCafferty, P.G., Sellai, A., Dawson, P. and Elabd, H. (1996) Barrier Characteristics of PtSi/p-Si Schottky Diodes. Solid-State Electronics, 39, 583-592. http://dx.doi.org/10.1016/0038-1101(95)00162-X

[33] Chand, S. and Kumar, J. (1996) Current Transport in $\mathrm{Pd}_{2} \mathrm{Si} / \mathrm{n}-\mathrm{Si}(100)$ Schottky Barrier Diodes at Low Temperatures. Applied Physics A, 63, 171-178.

[34] Tedesco, J.L. (2007) Electrical Characterization of Transition Metal Silicide Nanostructures Using Variable Temperature Scanning Probe Microscopy. Thesis, North Carolina State University, 232 p.

[35] Sze, S.M. and Ng, K.K. (2006) Physics of Semiconductor Devices. 3rd Edition, John Wiley and Sons, New York, 832 p.

[36] Ayyildiz, E., Turut, A., Efeoglu, H., Tüzemen, S., Sağlam, M. and Yoğurtçu, Y.K. (1996) Effect of Series Resistance on Forward Current-Voltage Characteristics of Schottky Diodes in the Presence of the Interfacial Layer. Solid-State Electronics, 39, 83-87. http://dx.doi.org/10.1016/0038-1101(95)00093-9

[37] Tung, R.T. (2001) Recent Advances in Schottky Barrier Concepts. Materials Science and Engineering, 35, 1-138. http://dx.doi.org/10.1016/S0927-796X(01)00037-7

[38] Korkut, H. (2013) Semiconductor Type Dependent Comparison of Electrical Characteristics of Pt/InP Structures Fabricated by Magnetron Sputtering Technique in the Range of 20 - 400 K. Nano-Micro Letters, 5, 34-39.

[39] El-Menyawy, E.M. (2014) Fourier Transform Infrared, Optical Properties and Schottky Junction Application of 2-[(antipyrinyl)-hydrazono]-3-oxo- $N$-pyridin-2-yl-butyramide Thin Films. Journal of Molecular Structure, 1068, 198203. http://dx.doi.org/10.1016/j.molstruc.2014.04.015

[40] Sun, K.W. and Fan, T.Y. (2010) Temperature Dependence of Current-Voltage Characteristics in Individual $\mathrm{Sb}_{2} \mathrm{Se}_{3}$ Nanowire. Materials Sciences and Applications, 1, 8-12. http://dx.doi.org/10.4236/msa.2010.11002

[41] Mtangi, W., Auret, F.D., Nyamhere, C., Janse van Rensburg, P.J., Chawanda, A., Diale, M., Nel, J.M. and Meyer, W.E. (2009) The Dependence of Barrier Height on Temperature for Pd Schottky Contacts on ZnO. Physica B, 404, 44024405. http://dx.doi.org/10.1016/j.physb.2009.09.022

[42] Meyaard, D.S., Cho, J., Schubert, E.F., Han, S.H., Kim, M.H. and Sone, C. (2013) Analysis of the Temperature Dependence of the Forward Voltage Characteristics of GaInN Light-Emitting Diodes. Applied Physics Letters, 103, Article ID: 121103 . http://dx.doi.org/10.1063/1.4821538

[43] Yüksel, Ö.F. (2009) Temperature Dependence of Current-Voltage Characteristics of Al/p-Si(100) Schottky Barrier Diodes. Physica B, 404, 1993-1997. http://dx.doi.org/10.1016/j.physb.2009.03.026

[44] Shroder, D.K. (2006) Semiconductor Material and Device Characterization. 3rd Edition, IEEE Press, Arizona State University. 
[45] Matsushita, H., Tojo, Y. and Takizawa, T. (2003) Schottky Properties of CuInSe ${ }_{2}$ Single Crystals Grown by the Horizontal Bridgman Method with Controlling Se Vapor Pressure. Journal of Physics and Chemistry of Solids, 64, 18251829. http://dx.doi.org/10.1016/S0022-3697(03)00247-6

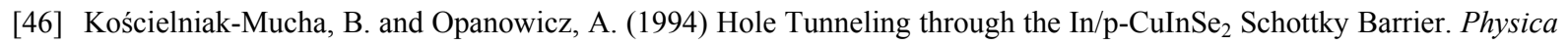
Status Solidi (a), 141, K67-K70. http://dx.doi.org/10.1002/pssa.2211410140

[47] Gorlei, P.N., Kovalyuk, Z.D., Orletskii, V.B., Sydor, O.N., Netyaga, V.V. and Khomyak, V.V. (2004) On the Mechanism of Current Passage in Metal/p-CuInSe 2 Structures. Technical Physics, 49, 658-659. http://dx.doi.org/10.1134/1.1758348

[48] Zhang, Z.W., Guo, H.Y., Li, J. and Zhu, C.F. (2011) Preparation and Characterization of Electrodeposited-Annealed $\mathrm{CuInSe}_{2}$ Thin Films for Solar Cells. Chinese Journal of Chemical Physics, 24, 225-229. http://dx.doi.org/10.1088/1674-0068/24/02/225-230

[49] Parihar, U., Ray, J.R., Kumar, N., Sachdeva, R., Padha, N. and Panchal, C.J. (2011) Impact of Annealing on CuInSe 2 Thin Films and Its Schottky Interface. Journal of Nano- and Electronic Physics, 3, 1086-1095.

[50] Farag, A.A.M., Yahia, I.S. and Fadel, M. (2009) Electrical and Photovoltaic Characteristics of Al/n-CdS Schottky Diode. International Journal of Hydrogen Energy, 34, 4906-4913. http://dx.doi.org/10.1016/j.ijhydene.2009.03.034

[51] Chawanda, A., Coelho, S.M.M., Auret, F.D., Mtangi, W., Nyamhere, C., Nel, J.M. and Diale, M. (2012) Effect of Thermal Treatment on the Characteristics of Iridium Schottky Barrier Diodes on n-Ge ( $\left.\begin{array}{lll}1 & 0 & 0\end{array}\right)$. Journal of Alloys and Compounds, 513, 44-49. http://dx.doi.org/10.1016/j.jallcom.2011.09.053

[52] Karataş, Ş., Çakar, M. and Türüt, A. (2014) On the Electrical Characteristics of the Al/rhodamine-101/p-Si MS Structure at Low Temperatures. Materials Science in Semiconductor Processing, 28, 2-9.

[53] Reddy, V.R., Reddy, M.S.P., Kumar, A.A. and Choi, C.J. (2012) Effect of Annealing Temperature on Electrical Properties of Au/Polyvinyl Alcohol/n-InP Schottky Barrier Structure. Thin Solid Films, 520, 5715-5721. http://dx.doi.org/10.1016/j.tsf.2012.04.020

[54] Gray, J.L., Schwartz, R.J. and Lee, Y.J. (1994) Numerical Modeling of CuInSe 2 and CdTe Solar Cells. ECE Technical Reports, Paper 173, Purdue University.

[55] Bayhan, H. and Ozden, S. (2007) Frequency Dependence of Junction Capacitance of BPW34 and BPW41 p-i-n Photodiodes. Pramana Journal of Physics, 68, 701-706. 
Scientific Research Publishing (SCIRP) is one of the largest Open Access journal publishers. It is currently publishing more than 200 open access, online, peer-reviewed journals covering a wide range of academic disciplines. SCIRP serves the worldwide academic communities and contributes to the progress and application of science with its publication.

Other selected journals from SCIRP are listed as below. Submit your manuscript to us via either submit@scirp.org or Online Submission Portal.
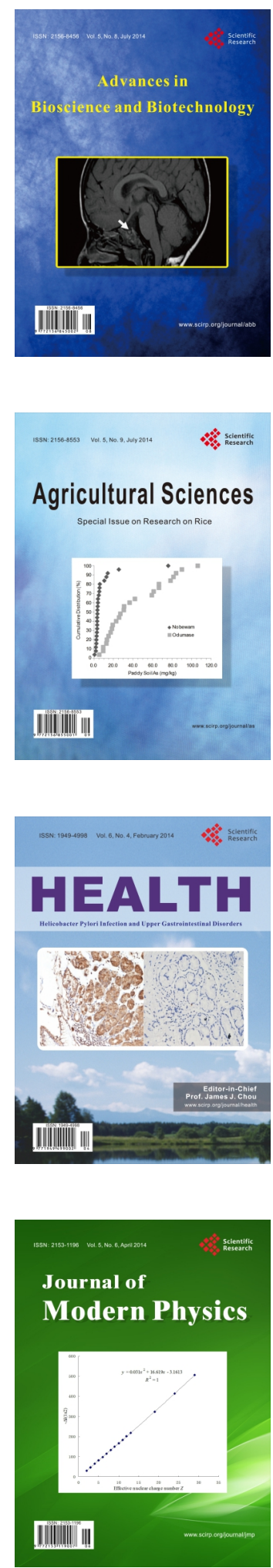
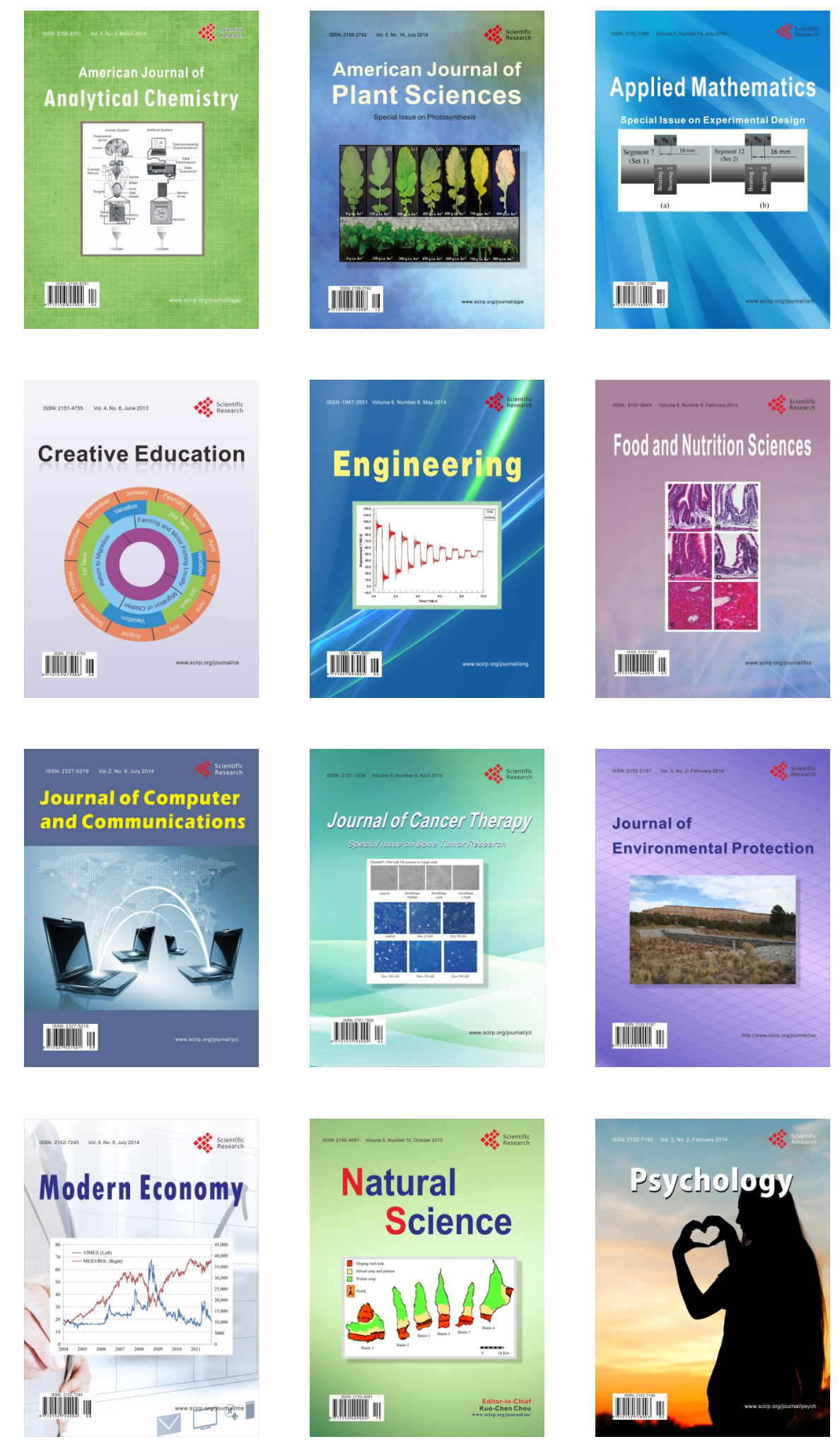